the work. Much labor has been expended upon the grounds in erecting fences, putting up temporary buildings, and arranging for future operations. A large quantity of material has been prepared and is already at hand.

The foundation of the centre building, connecting corridors, and two of the buildings of one wing have been laid, and the work is being rapidly pushed forward.

The appropriations thus far have been $\$ 300,000$.

\title{
CASE OF EXCESSIVE HYPODERMIC USE OF MORPHIA. THREE HUNDRED NEEDLES REMOVED FROM THE BODY OF AN INSANE WOMAN.
}

REPORTED BY JUDSON B. ANDREWS, M. D.

A woman, thirty years of age, single, seamstress, with no hereditary tendency to insanity; but was of a highly nervous and excitable organization, emotional and irregular in feeling; at times buoyant and lively, and then gloomy and depressed. Her health during early life was delicate, though she suffered from no definite form of disease. At the age of 20, in April, 1862, she was seized with pain in the head. It was of short duration, but very severe, and during its continuance the patient was delirious. Attacks of the same character, both in the severity of the pain and the mental disturbance have occurred since, at intervals of from one to three months.* In 1864, she had acute rheumatism, and in 1865 , a severe attack of diphtheria.

* From the subsequent history of the patient, especially while in the asylum, we are led to believe that these attacks of delirium took place at menstrual periods. 
After the local disease of the throat had apparently subsided, vomiting supervened, and was repeated every few hours for some five weeks. To relieve this condition and procure sleep, hypodermic injections of mor, phia were successfully employed, for about one weekand the patient rapidly regained her health. Some two years after this, or in July, 1867, she had an attack of inflammation of the bowels and peritoneum, and for four weeks was delirious most of the time. She improved somewhat in health, but for the four months succeeding, had frequent attacks of frenzy, during which she often threatened to take her own and her mother's life, and became very difficult to control. In October following, she had improved so far as to pass from the immediate charge of her physician. Soon after this, he ascertained she was using hypodermic injections of morphia, to relieve pain in her limbs and different parts of her body. I quote from his letter:

I was informed that she was using it, (morphia,) to a considerable extent, and called immediately to explain to her the effects and danger attending the practice. I believe every effort was made that could be, to prevail upon her to desist, but all to no purpose. She was cunning and artful, and would almost always study out some plan to get the morphia. She has used as much as two drams in a week, in one or two well authenticated instances. The usual amount was one dram per week. She used but little, if any, for three or four months before she was sent to the asylum, for it was very difficult for her to get it. She has acted very strangely ever since her first sickness. She has been truly a mystery, which no one could solve.

Her mother says:

That for years she has complained of pain, and pressed her hand on either side of her head, with the exclamation, "Oh mother, mother, I shall die!" That for six years she has complained of such soreness of the head that when she passed her hand over it, in smoothing her daughter's hair, she would cry out : "Oh mother, don't; it hurts me so!" That five years ago, in 1867 , she was 
obliged to call in help, as the patient threatened and intended to take her own life. That both before and after she began the use of morphia, her conduct was peculiar and erratic ; that she was emotional, and easily disturbed by trifles. That after the morphia habit was known, her conduct for many years preceding, was wrongly attributed to this cause.

A few weeks before she was sent to the asylum, she passed into an acutely maniacal condition, in which she was sleepless, ate little and irregularly, lost flesh and strength rapidly, and became quite feeble. She was destructive of clothing, pulled her hair out, was noisy, incoherent, and violent; opposed care, wandered about, and was with difficulty controlled. In this condition, she was admitted to the institution, on the 5th of May, 1871. She was carried to the ward, and placed in bed. Examination revealed scars and ecchymosed spots, cov. ering nearly the whole of the body which could be reached by her own hand. She asserted that she had employed the hypodermic injections for three and onehalf years, once, and much of the time twice a day, making in all about two thousand injections; that during the last few months of its continuance, she had used a dram and one-half of morphia per week; that she inserted the needle perpendicularly to the surface, and often carried its full length into the tissues. For two days she was sleepless, and retained no nourishment. Chloral, in thirty grain doses was then administered, which was tolerated by the stomach, and secured sleep. The vomiting gradually became less frequent, and soon ceased. She ate well, gained flesh and strength, all maniacal symptoms subsided, and in twenty days she was up and about the ward. Menstruation, as she said, had been suppressed for two years. As she complained of pain in the back, and other symptoms which usually preceded it, she was placed on use of capsules of apiol, and on the 24th of June, began to 
menstruate, but the flow was scanty, and accompanied by much pain.

During the month following, she steadily gained in mental strength, and became quite stout. At time of next menstrual period, the right breast swelled to an extraordinary size, so that we were obliged to suspend it with adhesive straps. It was hard, and extremely sensitive to the touch. This condition of swelling and tenderness, extended in a narrow ridge to the spine. The state of the breast was at first supposed to be ow. ing to the sympathetic action of the organ, with the renewed activity of the menstrual function. For two weeks, applications were employed, without success, to relieve the pain and tension. At this time, on the 13th of August, the patient in rubbing her hand over the breast, discovered an elevated point, just under the skin, which on pressure, gave a pricking sensation. This was cut down upon, and a broken needle extracted. On the 15th, another needle was removed. The breast was now inflamed, and extremely sensitive. August 28, another needle was taken out. August 29, menstruation began again. The flow was profuse, and she became at once delirious. Was talkative, restless, profane and obscene, and pulled her hair out. She continued in this condition some twelve hours, and, as she stated, the next day, was entirely unconscious of what had occurred.

From this time till September 28, from one to five needles were removed daily from the breast. Menstruation then occurred again, and was characterized as before by a similar attack of mental disturbance. After this, during the months of October and November, needles were taken from various parts of the body; from the left breast, the abdominal parietes the Mons Veneris, the labia, and vagina. Of these latter, some 
passed across the urethra, and rendered urination diffcult and painful; others across the vagina, either end being imbedded in opposite sides. Some were removed from the thighs, from the leg, down to the ankle, from the buttocks, from about the anus, from the back as high up as between the shoulders. The largest number extracted in any one day, was twelve.

On one occasion, ether was administered, but the difficulty experienced in bringing her under its influ. ence, and the mental disturbance produced by it were so great that it was not again resorted to. During the whole period, to her final illness, she retained her flesh, though she ate and slept irregularly, under use of tonics and sedatives. She was in a variable mental state, at times irritable, petulant, fault-finding, attempting to create ill-feeling between attendants, and demand. ing unnecessary care and waiting upon. At other times, she was abnormally cheerful, gay, pleasant, and fulsome of praise of all around her.

For the first two months, but comparatively little pain was felt in the extraction of the needles. The skin was thickened, harsh and dry, and almost insensible, from the prolonged and distributed use of the injections. Afterward, she suffered acutely, and often begged, with tears, that their removal might be post. poned from day to day. About a month before death, she had an attack of localized pneumonia, affecting the lower portion of right lung. This was accompanied by stridulous breathing, spasm of the glottis, globus hyster. icus, crying, and other hysterical manifestations. It was followed by an attack resembling muscular rheumatism, characterized by great pain and hyperæsthesia of surface. The right arm was swelled, hot and extremely sensitive. It was supported on a pillow and kept bathed in anodyne lotions. She lost appetite and

Vor. XXIX.-No. I.-B 
Journal of Insanity. [July,

sleep, became much depressed, and gave up all hope of recovery. Her tongue became dry and brown, pulse rapid, secretions offensive, and mind very feeble. A diarrhœa supervened and the evacuations of bowels and bladder were involuntary. She became unconscious, and finally comatose, and died on the 25 th of December, 1871.

No needles were removed during the two last weeks; 286 were taken from her body during life; 11 were found in the tissues after death; 3 were passed from the rectum during sickness; making a total of 300 needles and pieces. Of this number, 246 were whole, and 54 were parts of needles. One was a No. 1 sewing machine needle, and several were bent. They varied in size from No. 4 to No. 12. As regards position in the body, they were distributed about as follows : in right breast, 150 ; left breast, 20 ; abdomen, 60 ; genitals, 20 ; thighs and legs, 30 ; back, 20 . Of those removed after death, $\check{0}$ were found in the right and 3 in the left breast; one in a small abscess in the epigastric, and one in the right iliac region, the point impinging upon the peritoneum, which was discolored with rust; and one in the upper part of lower lobe of left lung. The presence and position of the needles were indicated to the patient by the pricking sensation occasioned by muscular movements. They were removed in a few instances at first, by cutting down upon them. This proved to be a painful, and from the move. ments of the needles in the tissues, a difficult process. -Hemorrhage from the small vessels, at times, gave some trouble. Afterwards, by manipulation, the ends of the needles were engaged between the thumb and forefinger, and the points, forced through the skin, were seized and the needles extracted with forceps. Sometimes much forca was required to withdraw them. They 
changed position quite readily, and frequently moved from one to two inches in the day. They produced little local irritation or trouble beyond the pricking sensation, and did not seem to have contributed in any notable degree toward producing the fatal result. In regard to the presence of this large number of needles in the system, no information could be obtained. The patient repeatedly and persistently denied any knowledge of having introduced them, either by the stomach or through the skin. Her mother, who visited the Asy. lum, could throw no light upon the subject, and was entirely ignorant of the fact until informed by us. She however, recalled the circumstance that the patient purchased, at one time, ten papers of needles, and could account for only two of them. They were not obtained or introduced while in the Asylum. She was under strict surveillance, and had no means of obtaining any number of needles, and those removed were all rusted and bore evidence of having been a long time in the body. The stomach was closely examined after death, and was in a perfectly healthy condition, with no evidence of any previous inflammatory action.

The only theory, which seems to us at all tenable, is, that they were introduced through the skin, while she was under the influence of morphia, hypodermically administered, and while suffering from hysteria. That some were found in positions where they could not have been inserted by the patient, can be accounted for by their movements in the tissues, which were observed so often during the life of the patient.

The diseased condition of the brain and its mem. branes was a cause sufficient to account for the abnormal mental action and conduct of her who had been "truly a mystery which no one could solve." We close this remarkable case with a transcript of the post-mortem examination. 
Autopsy.-Rigor present, body well nourished ; an-te rior surface thickly studded with small cicatrices; abdomen covered with thick layer of fat. A small ab. scess in abdominal wall, two inches above umbilicus, three inches by one and one-half, was filled with pus, and contained one needle. A second abscess, two inches above and to the right of the symphysis pubis, immediately under Pouparts ligament, contained another needle. This pressed upon the peritoneum, which though discolored by rust, was not inflamed. From the right breast, one whole and four broken needles, and from the left, one whole and two broken needles, were removed.

Head.-Arachnoid opaque and thickened over right hemisphere. The left hemisphere was covered by a thin layer of pus, contained in the sub-arachnoid space. Marked depression of convolutions at vertex of both hemispheres. The brain substance was firmer than normal. The ventricles were empty, and the choroid plexus contained numerous small cysts upon its surface, filled with serum.

Thorax.-The lower lobe of the right lung was hepatized. A whole needle was found in the upper part of the lower lobe of the left lung.

Abdomen.-The liver was soft and fatty, and the spleen enlarged; kidneys were normal. The stomach was subjected to a critical examination. It was found normal, and there was no evidence that the needles were introduced into the system through that organ. 